\title{
Assessment of the flood disaster management plans for the medical services in Tokyo and Fukuoka, Japan
}

\author{
M. Takezawa ${ }^{1}$, H. Gotoh ${ }^{1}$, K. Suzuki ${ }^{1}$, Y. Kakehi ${ }^{2}$ \\ \& T. Yamamoto ${ }^{3}$ \\ ${ }^{I}$ Nihon University, Japan \\ ${ }^{2}$ Fukuoka City, Japan \\ ${ }^{3}$ Chuo College of Technology, Japan
}

\begin{abstract}
Recently, large scale flooding disasters due to abnormal weather have been reported worldwide. These flooding disasters have caused severe damage and have claimed many lives. The medical services play an important role in flood disasters. In this paper, a disaster management plan for the medical services is described in terms of governmental policy, utilising questionnaire survey results, etc. The target areas used for the survey are the lowlands from the former flood disaster areas in Tokyo and Fukuoka, Japan. The policy of the Japanese Government regarding large scale flood hazards has been discussed by a team of experts. Moreover, some flood hazard prevention methods were proposed by the disaster risk management offices of the local governments of Tokyo and Fukuoka. The survey of flood preparedness for the medical services was sent and collected by mail.

The main results and conclusion are as follows:

It was clear from the questionnaire results that the flood hazard measures of the medical services in large cities such as Tokyo and Fukuoka are fairly poor, although the Japanese government and local governments do provide a guide for the event of a disaster. To reduce disaster risk, it is necessary to direct the promotion of an instrument that can provide guidance for the building and planning of cities and towns in the prevention of flood hazards, to establish a set of capacious shelters, to secure evacuation routes, etc. within a guide that will illuminate a crisis consciousness for flood hazards.

Keywords: medical service, flood preparedness, questionnaire, flooding hazard.
\end{abstract}




\section{Introduction}

Flooding is a dangerous disaster that not only severely damages natural resources but also results in loss of life. Flood disasters are usually caused by heavy rainstorms that overflow bodies of water or inundate sections of land. Flood preparedness is largely dependent on two elements: first, the ability of the relevant national, local and community institutions to orchestrate communication; and second, determining and prioritizing the content of communications on the basis of user needs and priorities. The lead time of the hydrologic forecasts is very short and people do not fully comprehend danger-level terminology. There is no mechanism for relating any forecast information with users' needs at specific locations. People have different capacities and vulnerabilities in regards to the dissemination of information due to their different roles and conditions and are therefore affected differently by a disaster. In many contexts, people are better connected to the early warning mechanisms due to their movement in public spaces and access to various channels of communication, such as radio, TV, informal community networks and interaction with officials. Japan has suffered extensive damage and casualties from frequent flooding and the medical services are very important for treating the wounded and injured when disaster strikes. The primary medical services in this paper refer to the large hospital where sick or injured people receive medical treatment as inpatients and the clinic where medical treatment is provided to people as outpatients. Emergency medical services are especially important in the event of a flood disaster.

\section{Past flooding disasters in Japan}

Japan consists of a series of small islands making it susceptible to a number of natural disasters. Typhoons are massive storms that can ravage the islands with high winds and storm surges. Typhoon Vera that hit Ise Bay on the Pacific Ocean of the midland in Japan in July 1959 killed more than 5,000 people and left more than 1.5 million homeless. The rainy season in Japan is from May through to July. Heavy rains fed by the warm ocean waters surrounding Japan can cause significant flooding and mudslides on the islands [1]. Typhoon Kathleen struck the entire Kanto Region in Japan on September 15, 1947. Heavy rains caused the Arakawa and Tone Rivers to overflow and the resulting floods killed 6 people, left 2 people missing and 3 people injured in the Tokyo metropolitan area [2]. Typhoon Kitty struck the Tokyo/Yokohama area between August 31 and September 1, 1949. A total of 18 people were killed and the number of injured reached 104 people due to rainfall-induced flooding and landslides [3]. Typhoon Ida in 1958 was the third deadliest typhoon in Japan. Ida caused torrential flooding in southeastern Japan, resulting in over 1,900 mudslides [4]. There were a total of 36 deaths, with 3 people missing. The Kyushu district of southern Japan suffered extensive damage from flooding in 2012 [5]. At least 20 people were killed by flooding, 7 people were missing and 
approximately 250,000 people were ordered to evacuate. Evacuation orders affected nearly 85,000 households in the Kyushu district and school gyms were being used as evacuation centers. More than 2,600 houses were destroyed by the flooding. Heavy rainfall caused by a stationary front inundated the Kyushu district in 2003 [6]. During this heavy rainfall, 1,352 houses were flooded when the Mikasa River overflowed its banks in Fukuoka City. A flood disaster also occurred in Fukuoka City in 1999 [7]. A disaster prevention plan based on internet real-time rainfall and water level information had been established in a hotel after the disaster. Water sealing plates were installed according to this plan and this hotel escaped flood damages. This shows the importance of examining the methods for utilizing real-time rainfall information. The North Kyushu Flood hit Northern Kyushu in 1953 [8]. The torrential rain during the rainy season, amounting to more than $1,000 \mathrm{~mm}$ on Aso and Hikosan mountains, caused great flooding in many of the rivers, including the Chikugo River, and left more than 1,000 people either dead or missing. A total of 450,000 houses were flooded and $1,000,000$ people suffered from the flood. Fundamental changes in flood control in the Kyushu area were needed and flood control standards have now been established to prevent further floods.

\section{Flooding prevention and medical services in Japan}

For effective disaster management, the national government, local governments and a wide range of relevant partners designated that public corporations should formulate disaster management plans and carry them out appropriately, based on the Disaster Countermeasures Basic Act (9). To protect national land as well as citizens' lives, livelihoods and property from disasters is a national priority. The turning point for strengthening the disaster management system came after the immense damage caused by the Isewan Typhoon (Typhoon Vera) in 1959 and led to the enactment of the Disaster Countermeasures Basic Act in 1961, which established a comprehensive and strategic disaster management system. The main contents of the Disaster Countermeasures Basic Act are (1) Definition of responsibilities for disaster management, (2) Disaster management organizations, (3) Disaster management planning system, (4) Disaster prevention and preparedness, (5) Disaster emergency response, (6) Disaster recovery and rehabilitation, (7) Financial measures and (8) State of Disaster Emergency.

Japan is prone to a variety of water and wind-related disasters including flooding, landslides, tidal waves and storm hazards, owing to meteorological conditions such as typhoons, active weather-front systems and geographical conditions such as precipitous terrains and steep rivers, as well as settlement conditions, in which many of the cities are built on river plains. One-half of the population is concentrated in possible inundation areas, which account for about $10 \%$ of the national land. Although there has been a large reduction in the area inundated by floods owing to soil conservation and flood control projects over many years, the amount of general assets damaged in flooded areas has increased in recent years. Additionally, as a long-term trend, there is an increasing 
tendency of downpours throughout the country. In order to reduce damage caused by severe weather disasters, structural measures such as improving rivers, dams and sewage systems and non-structural measures such as preparing hazard maps and providing disaster information must be promoted in an integrated manner. As non-structural countermeasures, the warning and evacuation systems of the possible inundation areas and landslide-prone area have been developed in accordance with the Flood Control Act and the Act on Promotion of Sediment Disaster Countermeasures for Sediment Disaster Areas. Both laws were amended in 2005 to intensify measures, including the familiarization of hazard maps and the identification of a method to disseminate disaster information to facilities caring for those who require assistance at the time of a disaster, such as elderly people, in the municipal disaster management plans. In light of a rising trend in heavy downpours in recent years, there is a strong need to fortify measures for rapid, effective evacuation and relief, in anticipation of large-scale flood disasters.

Emergency hospitals are a very important medical service in times of large-scale flood disaster. Emergency medical services are emergency services dedicated to providing out-of-hospital acute medical care, transport to definitive care and other medical transport for patients with illnesses and injuries that prevent patients from transporting themselves. The emergency medical services may also be locally known as paramedic services, first aid squads, emergency squads, rescue squads, ambulances, squad ambulance services, ambulance corps or life squads. The goal of most emergency medical services is to either provide treatment to those in need of urgent medical care, with the goal of satisfactorily treating the presenting conditions, or arranging for timely removal of the patient to the next point of definitive care. This is most likely an emergency department at a hospital. The term "emergency medical service" has evolved to reflect the change from a simple system of ambulances providing only transportation, to a system in which, actual medical care is given on scene and during transport. In some developing regions, this term is not used, or may be used inaccurately, since the service in question does not provide treatment to the patients, but only the provision of transport to the point of care. In most places in the world, the emergency medical service is summoned by members of the public (or other emergency services, businesses or authorities) via an emergency telephone number that puts them in contact with a control facility, which will then dispatch a suitable resource to deal with the situation. In some parts of the world, the emergency medical service also encompasses the role of moving patients from one medical facility to an alternative one; usually to facilitate the provision of a higher level or more specialized field of care but also to transfer patients from a specialized facility to a local hospital or nursing home when they no longer require the services of the specialized hospital, such as following successful cardiac catheterization due to a heart attack. In such services, the emergency medical service is not summoned by members of the public but by clinical professionals (e.g. physicians or nurses) in the referring facility. Specialized hospitals that provide higher levels of care may include services such as a Neonatal Intensive Care Unit (NICU), Pediatric Intensive Care Unit (PICU), 
state regional burn centers, specialized care for spinal injury and/or neurosurgery, regional stroke centers, specialized cardiac care (cardiac catheterization) and specialized/regional trauma care. In some jurisdictions, emergency medical service units may handle technical rescue operations such as extrication, water rescue and search and rescue. Training and qualification levels for members and employees of emergency medical services vary widely throughout the world. In some systems, members may be present who are qualified only to drive the ambulance, with no medical training. In contrast, most systems have personnel who retain at least basic first aid certifications, such as Basic Life Support (BLS). Additionally many emergency medical service systems are staffed with Advanced Life Support (ALS) personnel, including paramedics, nurses, or, less commonly, physicians. In order to make it possible to promptly and appropriately provide medical care to the injured, etc. when a large disaster occurs, the first medical care system of the Disaster Medical Assistance Team and medical aid unit, etc., the injured person transporting system, and the information exchanging system have been upgraded, with the focus on the disaster medical care coordinators. The Disaster Medical Assistance Team comprises of specially trained medical teams that are dispatched to disaster locations, such as natural disasters, to provide emergency medical care as quickly as possible. Damage estimates for an earthquake with an epicenter in the Tokyo metropolitan area predict extensive injuries and loss of life. To assure the effectiveness of rescue efforts through maintaining partnerships with each of the Tokyo Metropolitan Government disaster prevention organizations, the "Tokyo Metropolitan Government Regional Disaster Prevention Plan" establishes medical care systems during a disaster, including medical information gathering, initial medical care (dispatch of Tokyo Disaster Medical Assistant Team, triage), transportation of casualties and backup hospitals (disaster base hospitals). The disaster medical care steps are shown in Figure 1 $[10,11]$.

The Tokyo Disaster Medical Assistance Team is a group of medical personnel that are dispatched at the time of a disaster, such as a large earthquake or a large-scale traffic accident, to administer emergency medical treatment at the scene. In principle, each team has one doctor and two nurses. The Tokyo Disaster Medical Assistance Team made it a goal to have 22 hospitals and 700 members to cover each of the 12 medical care zones in Tokyo within the fiscal year 2006. During a disaster, it is important to effectively distribute limited medical resources, personnel and medicine to treat as many victims as possible. In line with that purpose, within the triage system, patients are treated or transported depending on the severity and urgency of their injuries. The triage criteria are shown in Table 1.

After triage, casualties will be taken to medical facilities by the Tokyo Fire Department transport, medical care team vehicles, helicopter, boat or some other form of transport. The Tokyo Metropolitan Government designates 70 hospitals in the Tokyo metro area as "Tokyo Disaster Base Hospitals" to expand and strengthen the backup hospital system during a disaster. These hospitals may display the designation of "Tokyo Disaster Base Hospitals" at their entrances. 
General hospitals will also make open beds available and temporarily enhance capacity as the disaster base hospitals cannot house all casualties. Because injuries during a disaster range from minor to severe, as a general rule doctors triage from the entrance of the medical care station.

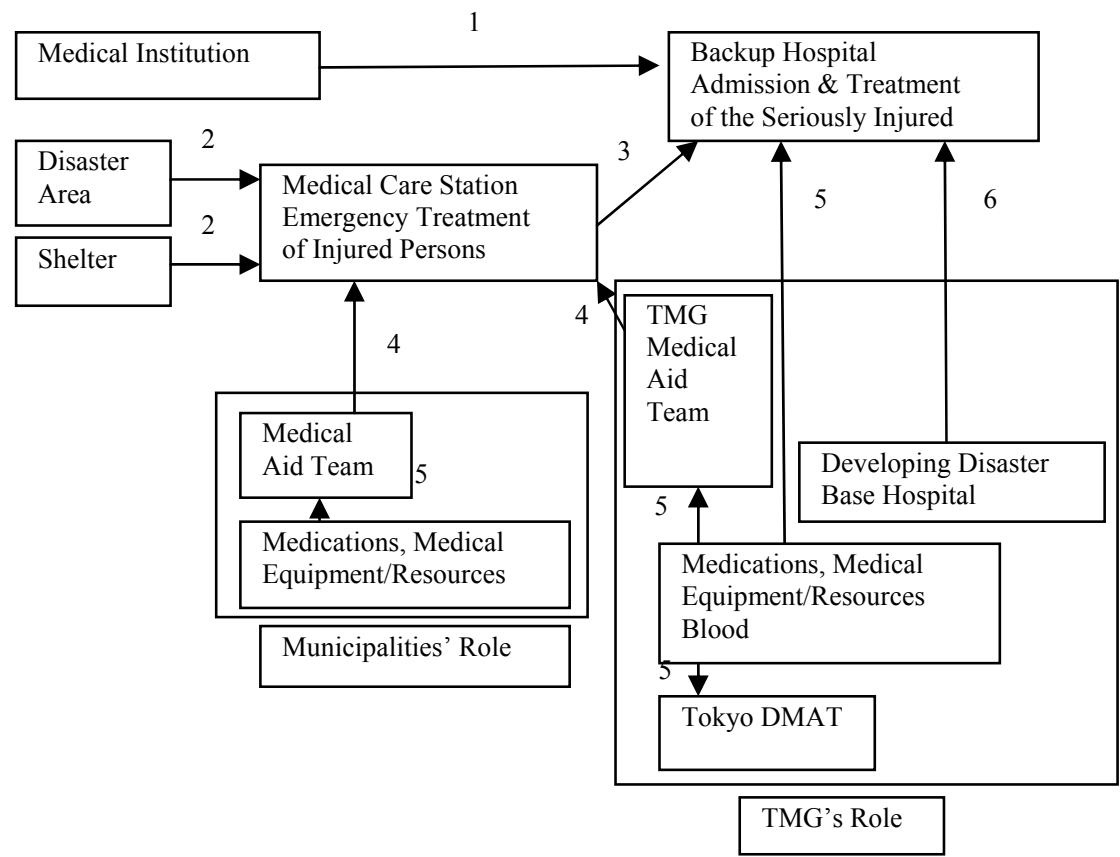

Figure 1: Disaster medical care steps [10]. 1: Person who receives limited medical care (this means someone who cannot receive medical care because medical institutions have been damaged). 2: Injured persons. 3: Serious cases. 4: Dispatch. 5: Supply. 6: Development.

Table 1: Triage criteria [10].

\begin{tabular}{|l|l|l|l|}
\hline Categories & Priority & ID Tag & Symptoms, etc. \\
\hline $\begin{array}{l}\text { Immediate } \\
\text { (Severe) }\end{array}$ & First & Red & $\begin{array}{l}\text { Requires immediate treatment to save life. } \\
\text { Symptoms include asphyxia, excessive bleeding, } \\
\text { state of shock. }\end{array}$ \\
\hline $\begin{array}{l}\text { Delayed } \\
\text { (Moderate) }\end{array}$ & Second & Yellow & $\begin{array}{l}\text { (1) Can have their treatment delayed and the } \\
\text { condition is not life threatening. } \\
\text { (2) Principally, when vital signs are stable. }\end{array}$ \\
\hline $\begin{array}{l}\text { Wait } \\
\text { (Minor) }\end{array}$ & Third & Green & $\begin{array}{l}\text { Those with minor injuries other than those outlined } \\
\text { above. } \\
\text { Does not require a specialist's care. }\end{array}$ \\
\hline Deceased & Fourth & Black & $\begin{array}{l}\text { Confirmed or obviously deceased. } \\
\text { Unlikely to be revived given cardiopulmonary } \\
\text { resuscitation. }\end{array}$ \\
\hline
\end{tabular}




\section{Questionnaire results}

The questionnaire was sent to 300 medical services of four wards (Katsushika, Edogawa, Sumida and Kotoh) along the Arakawa River and the Sumidagawa River in the Tokyo metropolitan area and seven wards (Higashi, Hakata, Cyuou, Minami, Jyonan, Sagara and Nishi) along the Nakagawa River and the Mikasagawa River in Fukuoka City, as shown in Figures 2 and 3. The Arakawa River is one of the principal rivers flowing through downtown Tokyo. The Arakawa River originates at Mt. Kobushi in Saitama Prefecture and empties into Tokyo Bay [12]. The Sumidagawa River flows through downtown Tokyo. The Sumidagawa River branches from the Arakawa River at Iwabuchi and flows into Tokyo Bay [13]. The Nakagawa River originates at Mt. Seburi and flows into Hakata Bay through downtown Fukuoka City [14]. The Mikasagawa River originates at Mt. Houman and flows into Hakata Bay joining some rivers [15].

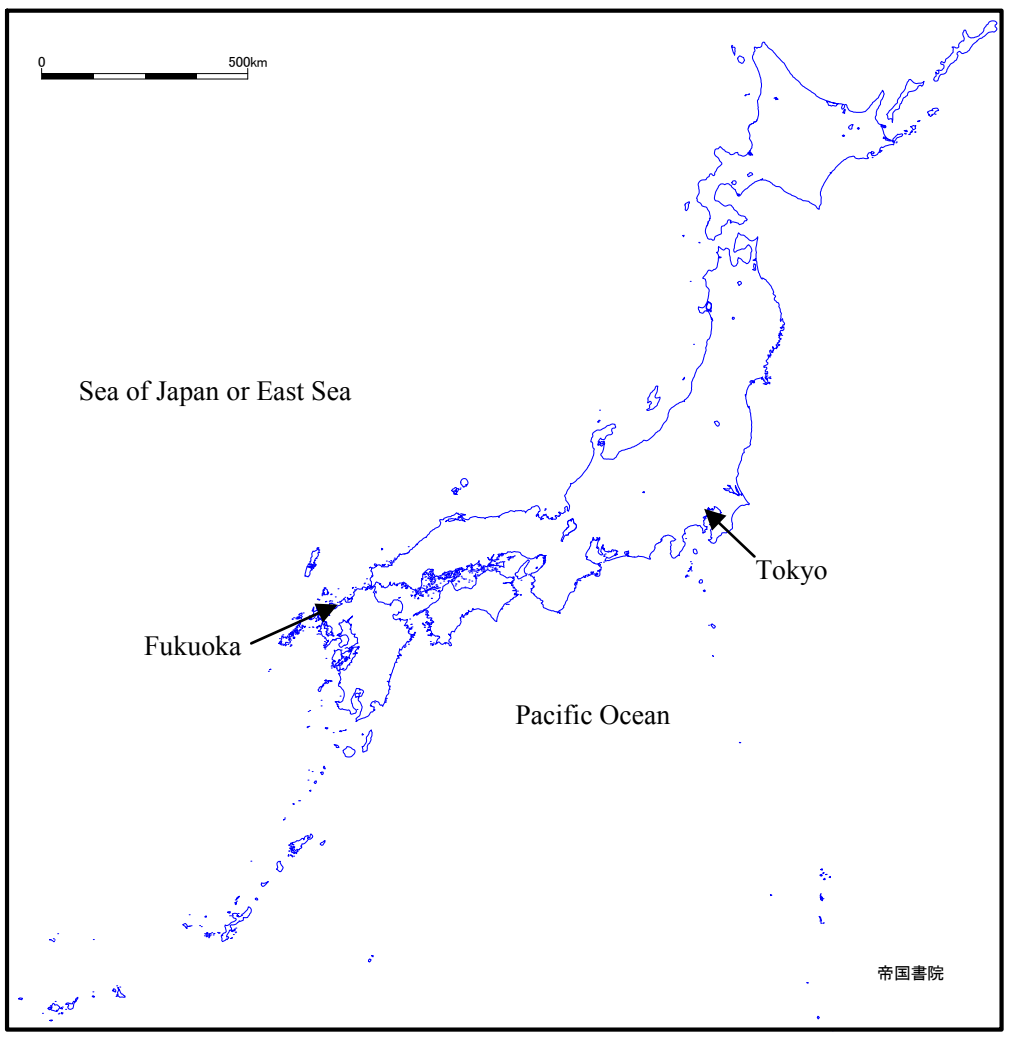

Figure 2: Map of Japan [16]. 


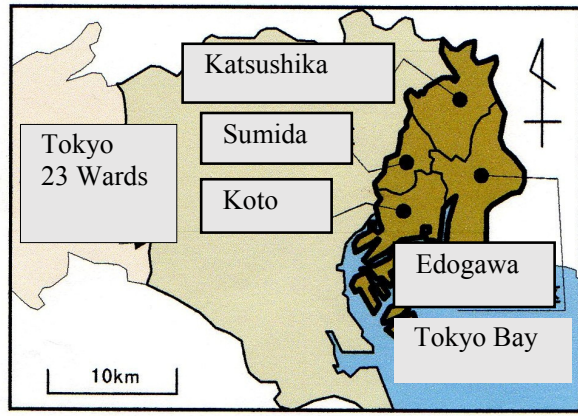

Tokyo metropolitan area

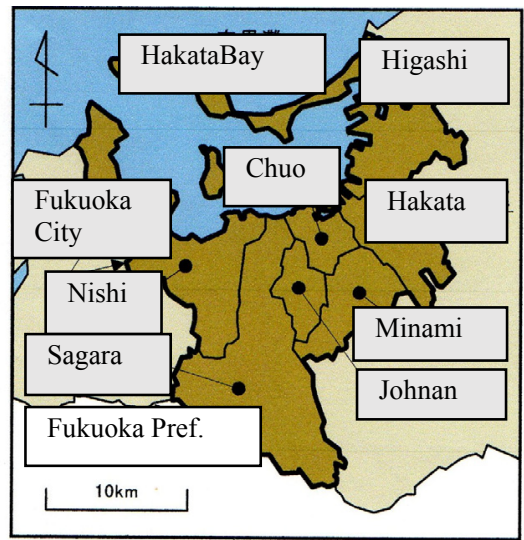

Fukuoka City

Figure 3: Locations of Tokyo metropolitan area and Fukuoka City.

The questions used within the questionnaire are as follows:

(1) Do you have facilities to accept patients for treatment? (yes or no)

(2) If the answer to (1) is yes, then how many beds do you have?

(3) How long has your medical service been active?

(4) What floors are the MRI, CT, X-ray centers?

(5) Does your medical service have auto-generators? (yes or no)

(6) If the answer to (5) is yes, how many stories are the auto-generators placed at?

(7) Has your medical service been damaged by flooding? (yes or no)

(8) Does your medical service have a flooding manual? (yes or no)

(9) Are you referring to following the flooding hazard maps provided by the Civil Service for evacuation? (yes or no )

(10) Do you think that the flooding management of your medical service is sufficient? (yes or no)

(11) If the answer to (10) is no, what are the specific flooding measures of your medical service?

(12) Does your medical service stockpile food and supplies? (yes or no)

(13) If the answer to (12) is yes, how much is stockpiled?

(14) If the answer to (12) is yes, how many stories does your medical service stockpile their food and supplies?

(15) Does your medical service stockpile medicines? (yes or no)

(16) If the answer to (15) is yes, how many medicines are stockpiled?

(17) If the answer to (15) is yes, how many stories does your medical service stockpile their medicines?

(18) Does your medical service hold flooding evacuation drills? (yes or no)

(19) Does your medical service provide an evacuation boat during flooding? (yes or no) 
(20) Is your medical service going to start with how timing of refuge for the flooding?

(21) Is the evacuation route secured? (yes or no)

(22) If the answer to (21) is no, what is the specific evacuation route?

(23) What other opinions do you have regarding the flooding preparedness measures of your medical services?

The results of the above questionnaire are given in Table 2 .

Table 2: Results of questionnaire (\%).

\begin{tabular}{|c|c|c|c|c|c|c|}
\hline No & Yes of $\mathrm{T}$ & No of $T$ & ? of T & Yes of F & No of $F$ & ? of $\mathrm{F}$ \\
\hline 1 & 30.1 & 69.9 & 0 & 20.6 & 79.4 & 0 \\
\hline 2 & \multicolumn{3}{|l|}{ Average } & \multicolumn{3}{|l|}{ Average } \\
\hline 3 & \multicolumn{3}{|c|}{ Average 27 years } & \multicolumn{3}{|c|}{ Average 20 years } \\
\hline 4 & \multicolumn{3}{|c|}{$1^{\text {st }} 75 \% \quad 2^{\text {nd }}$ over $25 \%$} & $1^{\text {st }}: 65 \%$ & \multicolumn{2}{|c|}{ nd over $35 \%$} \\
\hline 5 & 34.2 & 64.4 & 1.4 & 19.0 & 81.0 & 0 \\
\hline 6 & \multicolumn{3}{|c|}{$5^{\text {th }}$ under: $35 \% \quad 6^{\text {th }}$ over: $65 \%$} & \multicolumn{3}{|c|}{$5^{\text {th }}$ under: $40 \% \quad 6^{\text {th }}$ over: $35 \%$} \\
\hline 7 & 2.7 & 95.9 & 1.4 & 7.9 & 92.1 & 0 \\
\hline 8 & 9.6 & 90.4 & 0 & 9.5 & 90.5 & 0 \\
\hline 9 & 42.5 & 53.4 & 4.1 & 36.5 & 63.5 & 0 \\
\hline 10 & 4.1 & 87.7 & 8.2 & 14.2 & 81.0 & 4.8 \\
\hline 11 & \multicolumn{3}{|c|}{$\begin{array}{l}\text { Placement of sandbags and } \\
\text { cutoff plates }\end{array}$} & \multicolumn{3}{|c|}{$\begin{array}{l}\text { Raise the floor over the supposed } \\
\text { inundation depth }\end{array}$} \\
\hline 12 & 45.2 & 54.8 & 0 & 27.0 & 69.8 & 3.2 \\
\hline 13 & \multicolumn{3}{|c|}{172 meals } & \multicolumn{3}{|c|}{202 meals } \\
\hline 14 & \multicolumn{3}{|c|}{ Almost all on $1^{\text {st }}$ or $2^{\text {nd }}$ floor } & \multicolumn{3}{|c|}{ Almost all on $1^{\text {st }}$ or $2^{\text {nd }}$ floor } \\
\hline 15 & 60.3 & 35.6 & 4.1 & 52.4 & 41.3 & 6.3 \\
\hline 16 & \multicolumn{3}{|c|}{7 days/person } & \multicolumn{3}{|c|}{9 days/person } \\
\hline 17 & \multicolumn{3}{|c|}{ Almost $1^{\text {st }}$ or $2^{\text {nd }}$ floor } & \multicolumn{3}{|c|}{ Almost $1^{\text {st }}$ or $2^{\text {nd }}$ floor } \\
\hline 18 & 1.4 & 97.2 & 1.4 & 7.9 & 90.5 & 1.6 \\
\hline 19 & 0 & 98.6 & 1.4 & 0 & 96.8 & 3.2 \\
\hline 20 & \multicolumn{3}{|c|}{ Personal judgment } & \multicolumn{3}{|c|}{$\begin{array}{l}\text { Follow the evacuation advice of the } \\
\text { government }\end{array}$} \\
\hline 21 & 34.3 & 57.5 & 8.2 & 39.7 & 49.2 & 11.1 \\
\hline 22 & \multicolumn{3}{|c|}{ Narrow aisle for evacuation } & \multicolumn{3}{|c|}{ No place for evacuation } \\
\hline 23 & \multicolumn{3}{|c|}{$\begin{array}{l}\text { Money for remodeling the upper } \\
\text { floors } \\
\text { Simple manual pertaining to the } \\
\text { region } \\
\text { Specific indication for hazard }\end{array}$} & \multicolumn{3}{|c|}{$\begin{array}{l}\text { Check and maintenance of drainage } \\
\text { Raising awareness of hazard maps } \\
\text { Specific indication for dangerous } \\
\text { places }\end{array}$} \\
\hline
\end{tabular}

T: Tokyo Metropolitan, F: Fukuoka City. 


\section{Discussions by management}

There was flooding in the vicinity of the junction between the Uonogawa River and the Shinanogawa River in 2011. As a result, the $1^{\text {st }}$ floor of the Aorinosato special nursing home for the aged, shown in Figure 4, was flooded. For future reference, a hearing was conducted on the management of the home to discuss the situation during the flooding. (1) The location of the special nursing home for the aged was selected by considering the medical service, the welfare and the education for residents. (2) The hazard information was acquired by the crisis of home staff. (3) A manual was not prepared for flooding disasters, although one was prepared for earthquakes. Moreover, the flooding evacuation route was not prepared, although one was prepared in the case of a fire. (4)The food and the medicine were kept on the $2^{\text {nd }}$ floor or above. (5)The total amount of damage was $\$ 90,000$, but was not fully compensated because of the high cost of some of the instruments. (6)The reception room was carefully disinfected using antiseptics after the flood hazard. (7)The air conditioning was very important. It was clear that the home staff were able to meet the challenges posed by the flooding. In addition, they must endeavor to carry out retrieval at the home. The medical service should correspond to flooding hazards via the hazard manual as conducting fair action in the case of an emergency.

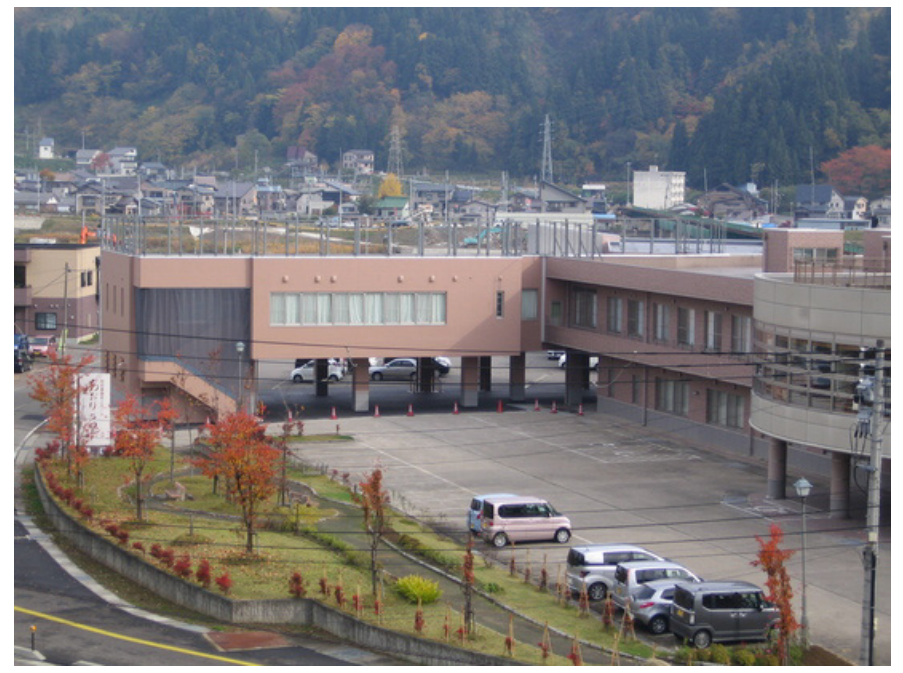

Figure 4: Aorinosato special nursing home for the aged [17].

\section{Conclusions}

The flood preparedness of the medical services was considered using the results from the questionnaire and discussion. The main findings are as follows: (1) Government grants are necessary for preparing flooding defense measures. 
(2) Convenient storage facilities for sectional water-barriers and defenses should be secured in the surrounding site. (3) Drainage channels are constructed and repaired using gutters, reservoirs and cisterns. (4) Emergency food, supplies and medicines of are to be kept on the floor above the maximum inundation water depth of flooding. (5) High-cost medical equipment, such as MRI, CT and $\mathrm{X}$-ray machines are to be placed on the highest floor possible, or their centers are to be constructed in waterproof rooms. (6) Medical services are to set up auto-generators and air conditioners in consideration of long-term stays due to the inundation. (7) The Japanese Government, the Tokyo metropolitan area and Fukuoka City are to ensure that medical services are practiced on a place higher than the predicted inundation depth. (8) Members of medical services should maintain crisis consciousness for flooding and also prepare a manual of flooding disaster measures. (9) It is necessary to perform flood evacuation drills. (10) The Disaster Imagination Game can be used to raise the awareness of evacuation in the event of flooding for those that have difficulty walking. (11) It is necessary to consider duly and discuss seriously among the civil service, the medical services and inhabitants how to transfer them from the devastated area to a safety area, and how to secure both the transport route and the transportation. Moreover, it is also important to construct a disaster center of placing on the access in the assignment of refuge buildings in cooperation with the neighboring facilities like schools, offices, corporation, etc. by the guidance of the government. It is clear from the above results that the disaster prevention of medical services in downtown Tokyo and Fukuoka is incomplete at present. In the future, it will be necessary to improve the disaster prevention of medical services, with focus on small children and senior citizens. Furthermore, the government should guide the city plans to strengthen measures against disasters and provide funding to improving the medical services in the event of future large-scale disasters.

\section{References}

[1] Wikipedia, the free encyclopedia, Typhoon Vera, http://en.wikipedia.org/ wiki/Typhoon Vera (2014/02/17).

[2] Wikipedia, the free encyclopedia, Typhoon Kathleen, http://ja.wikipedia. org/wiki/\%E3\%82\%AB\%82\%B9\%E3\%83\%AA\%E3\%83\%B. (2014), (in Japanese).

[3] Wikipdia, the free encyclopedia, Typhoon Kitty, http://ja.wikipedia.org/ wiki/\%E3\%82\%AD\%E3\%83\%86\%E3\%82\%A3\%E5\%8F\%B0. (2014).

[4] Wikipedia, the free encyclopedia, Typhoon Ido, http://en.wikipedia.ord/ wiki/Typhoon_Ida_(1958). (2014).

[5] The Japan Daily Press, "Kyushu rains, flooding subsides as death toll rises to 26", http://japandailypress.com/kyushu-rains-flooding-subsides-as death-toll-rises-to-28-1. (2014).

[6] Wikipedia, the free encyclopedia, Typhoon Soudelor (2003), http://en.wikipedia.org/wiki/Typhoon_Soudelor. (2003) (2014/02/17).

[7] Kusuda, T., The heavy rain in Fukuoka City, JSCE Vol. 84, Nov. 1999. 
[8] Wikipedia, the free encyclopedia, 1953 North Kyushu Flood, http://en.wikipedia.org/wiki/1953_North_Kyushu_Flood (2014/02/12).

[9] Cabinet Office, Government of Japan, Disaster Management In Japan, 2011

[10] Tokyo Metropolitan Government, Disaster Prevention Guide Book, http://www.bousai.metro.tokyo.jp/ (2014/02/17).

[11] Asia News Networks, Disaster base hospital in Japan fear flooding, http://www.asianewsnet.net/nws-40586.html.

[12] Wikipedia, the free encyclopedia, Arakawa (Kanto), http://ja.wikipedia. org/wiki/\%E8\%8D\%92\%E5\%B7\%9D. (2014/02/18).

[13] Wikipedia, the free encyclopedia, Sumida River, http://en.wikipedia.org/ wiki/Sumida_River (2014/02/18).

[14] Wikipedia, the free encyclopedia, Nakagawa, http://ja.wikipedia.org/ wiki/\%E9\%82\%A3\%E7\%8F\%82\%E5\%B7\%9D. (2014/02/18).

[15] Wikipedia, the free encyclopedia, Mikasagawa, http://ja.wikipedia.org/ wiki/\%E5\%BE\%A1\%E7\%AC\%A0\%E5\%B7\%9D (2014/02/18).

[16] Teikoku Shoin, White Map in Japan, http://www.teikokushoin.cojp/howto/ outline map/japan/.

[17] Social Welfare Service Corporation Ojiya KitauonumaWelfare Society, Aorinosato, http://ok-fukushikai.com/index.php?id=6 (Japanese). 